\title{
Measuring Individual Differences in the Tendency to Forgive: Construct Validity and Links With Depression
}

\author{
Ryan P. Brown \\ The University of Oklahoma
}

Four studies examine the construct validity of the Tendency to Forgive Scale (TTF), a brief measure of dispositional forgiveness. Study 1 showed that romantic partners' ratings of targets converged with targets' self-ratings, and Study 2 demonstrated that higher scores on the TTF were associated with lower offense accessibility. Study 3 examined the TTF's relation to self-reported depression symptoms, both independent of and interacting with attitudes toward forgiveness and dispositional vengeance. Lower TTF scores were associated with higher degrees of depression, especially for individuals with positive attitudes toward forgiveness or those low in dispositional vengeance, although neither of these latter variables displayed significant zero-order relations with depression. Finally, Study 4 examined relations between the TTF, dispositional empathy, another recent measure of dispositional forgiveness, and the dimensions of the Big Five, providing both convergent and discriminant validity evidence for the TTF.

Keywords: forgiveness; individual differences; mental health

$\mathbf{N}$ longer the sole province of theologians, the construct of forgiveness has experienced a recent surge in attention from research psychologists. During the past decade, social, personality, and clinical psychologists have begun to explore empirically how forgiveness occurs, under what conditions it tends to be granted, and what some of the mental health correlates and consequences of forgiveness may be. In a review of the empirical literature on forgiveness, McCullough (2000) noted that most research on forgiveness has focused either at the level of a specific offense or at the level of a particular dyadic relationship. However, despite progress in these areas, relatively little research to date has examined forgiveness at the level of a global disposition, across situations and relationships (Berry, Worthington, Parrott, O'Connor, \& Wade, 2001; Emmons, 2000; McCullough, 2000). It is at this level that the present research focuses.

\section{Construct Clarity}

As with many new research topics, construct clarity is currently a problem for the field of forgiveness research because there is yet no clear consensus as to what forgiveness really is and what it is not. For example, Enright and colleagues conceptualize forgiveness as a freely chosen act by a victim involving both a reduction in resentment and the offering of compassion, mercy, and love to the offender (Enright, Freedman, \& Rique, 1998; Enright \& The Human Development Study Group, 1991). This view also is reflected in Fincham's (2000) conceptualization of forgiveness, which labels the reduction in resentment as the "negative" dimension of forgiveness and the offering of compassion, and so forth, as the "positive" dimension. In contrast, McCullough et al. (1998) view forgiveness as primarily a function of a changed motivational state-specifically, the cessation of revenge and avoidance motives following an offense (for a related view, see McGary, 1989). If theorists agree on anything in their many definitions of forgiveness, it seems to be that forgiveness does not require reconciliation between a victim and an offender (see Fincham, 2000, for a cogent discussion of this issue).

The general lack of construct clarity within the field has manifested itself in the measures of forgiveness that have been developed. Nowhere is this more apparent than in the few investigations to date that have examined

\footnotetext{
Author's Note: I am grateful to Jennifer Bosson and Carolin Showers for their helpful comments on an earlier draft of this article and to Amy Summerville and Benjamin Bax for their help with data collection and entry. I also would like to acknowledge the encouragement of Daniel Gilbert, who first convinced me that forgiveness could (and should) be studied empirically. Correspondence concerning this article should be directed to the author at the Department of Psychology, The University of Oklahoma, 455 W. Lindsey, DHT \#705, Norman, OK 73019; e-mail: rpbrown@ou.edu.
}

PSPB, Vol. 29 No. 6, June 2003 759-771

DOI: $10.1177 / 0146167203252882$

(C) 2003 by the Society for Personality and Social Psychology, Inc. 
forgiveness at the dispositional level. Most existing measures of forgiveness operate at the level of specific offenses, or at the level of specific relationships (McCullough, 2000). Currently, only the measures described by Gorsuch and Hao (1993), Mauger et al. (1992), and Berry et al. (2001) purport to assess forgiveness at the level of a general disposition. Of these three, only Berry et al.'s Transgression Narrative Test of Forgivingness does so without directly conflating forgiveness with other constructs. Beyond these three measures, all other measures to date are either focused on a different level of the construct (offense specific or dyadic) or are not measures of forgiveness at all. Rather, they are measures of vengeance, aggression, or related but distinguishable constructs. Making clear distinctions between such constructs is important if progress is to be made in the field of forgiveness research. For example, although someone who takes vengeance against an offender could clearly be said not to have forgiven, it is not necessarily the case that someone who fails to take vengeance-or who fails to endorse vengeance-related items on an attitude scale-has forgiven at all. Thus, a trait measure of vengeance does not necessarily make a good measure of dispositional forgiveness. This distinction is important not just for examining a particular theory of forgiveness but also for assessing the practical consequences of forgiveness for mental health and well-being (at any level of analysis, including the dispositional level). Below, I discuss the existing measures of dispositional forgiveness in more detail.

\section{Critique of Previous Measures}

Within the burgeoning forgiveness literature, Gorsuch and Hao's (1993) research is perhaps the single most widely cited evidence for the "multidimensional" nature of dispositional forgiveness (e.g., McCullough, 2000). However, a close examination of Gorsuch and Hao's empirical evidence calls this conclusion into question. As part of a broad-based survey on religion by the Gallup organization, Gorsuch and Hao (1993) asked participants how they tend to respond when they feel that another person has "deliberately done something wrong" to them (p. 335). Participants were then given a list of eight potential responses from which they were to select all that typically applied to them. Example response options were "Try to get even in some way," "Try to forgive the other person," and "Pray to God for comfort and guidance." Next, participants were asked why they typically respond in the manner they indicated in the first question, and again they were given a list of potential responses, such as "Helps me feel better and lessens the pain" and "It is something that God requires." A third question asked participants why they do not always try to forgive the other person. Available response options were reasons such as "I see no reason to do so" and "God does not require it." Finally, participants were asked how they typically act when they themselves have done something wrong to another person, with a corresponding list of possibilities such as "Apologize" and "Ask God's forgiveness." The results of a factor analysis on the response items endorsed by participants indicated a multifactorial solution, from which the researchers concluded that forgiveness is a multidimensional construct composed of a "forgiving motive" factor, a "religious response" factor, a "forgiving pro-action" factor, and a "hostility" factor.

It is important to note that Gorsuch and Hao did not code "forgiving" versus "unforgiving" responses to create a scale to measure trait forgiveness, and it is well they did not. What would it mean to sum across such a panoply of response options that included not only cognitive and behavioral responses to being wronged but also motivations for these responses and responses to being a wrongdoer? Given this heterogeneity of items in the researchers' factor analysis, is it any surprise that the outcome of their analysis was "multifactorial"? Indeed, the surprise would have occurred if it had not been multifactorial. Furthermore, the utility of any scale built on their work would appear to be extremely limited, rooted as their items are in religious practices, beliefs, and motives. Thus, an agnostic individual might receive a low score on such a scale not because he or she typically fails to forgive others but rather because he or she does not involve God in the process.

A second measure often cited as a measure of a forgiving disposition is Mauger et al.'s (1992) Forgiveness of Others Scale (FOO). Unlike Gorsuch and Hao (1993), Mauger et al. explicitly set out to devise a measure of individual differences in the forgiveness of others. The resulting 15-item FOO, which was part of a larger battery of items (including items tapping forgiveness of self), demonstrated excellent 2-week stability $(r=.94)$ and reasonable internal consistency $(\alpha=.79)$. However, this scale, too, suffers from a lack of construct clarity. Many of the items of the FOO actually pertain to vengeance attitudes and behaviors (e.g., "If a person hurts you on purpose, you deserve to get whatever revenge you can" and "When other people insult me, I tell them off"). In fact, in a recent investigation of vengeance and well-being, McCullough, Bellah, Kilpatrick, and Johnson (2001) actually used seven items from the FOO as their measure of a vengeance-seeking disposition. If, as has already been asserted, vengeance and forgiveness are not polar opposites, then treating the FOO as a measure of dispositional forgiveness may be problematic.

But without conceding this argument, a careful examination of the 15 items of the FOO reveals an unfortunate conflation of constructs. For instance, Mauger et al. 
include items such as "I often use sarcasm when people deserve it," "I feel that other people have done more good than bad for me," and "I believe that when people say they forgive me for something I did, they really mean it." Such items clearly do not assess the dispositional tendency to forgive. Although the preponderance of items on the FOO actually assess vengeance-seeking behaviors or attitudes about the appropriateness of vengeance, the scale overall lacks conceptual coherence to such an extent that its utility for capturing any single disposition is questionable.

Finally, during the preparation of this article, a third measure of forgiveness was published by Berry et al. (2001): the Transgression Narrative Test of Forgivingness (TNTF). Unlike previous approaches, theirs appears, on the face of it, to be a relatively "pure" measure of a forgiving disposition. Berry et al.'s TNTF contains five offense scenarios that participants are asked to imagine happened to them. Following each of these hypothetical events, participants are asked to indicate the extent to which they believe they would forgive the offender (using a single forgiveness item). These predictions are then summed across the five scenarios to create a dispositional forgiveness score.

One advantage of this approach, as Berry et al. note, is that such a scale does not rely on any particular definition of forgiveness, thus allowing its adoption by theorists and practitioners who hold competing definitions. Of course, those who complete this scale, similar to the researchers who use it, also may have competing views of what forgiveness means. Some will confuse forgiveness with vengeance, with reconciliation, or with excusing an offender's actions (as previous researchers have). In addition, asking individuals to predict how they might respond to a hypothetical event also can be an uncertain enterprise, as others have argued concerning the prediction of emotion states in general (e.g., Gilbert, Pinel, Wilson, Blumberg, \& Wheatley, 1998; Harris, 2002; Lazarus, 1995; Parkinson \& Manstead, 1992, 1993; Russell \& McAuley, 1986) and forgiveness in particular (Lieberman \& Gilbert, 1998). Despite these potential shortcomings, the TNTF undoubtedly represents the best measure to date of dispositional forgiveness. Although limited evidence currently exists in support of the predictive validity of the TNTF, Berry et al. (2001) report that scores on this scale are positively associated with agreeableness, extraversion, and conscientiousness ( $r$ s between .19 and .33 ) and negatively associated with neuroticism, anger, and hostility ( $r$ s between -.27 and .43). They also report that the TNTF was virtually uncorrelated with aggression. In addition, Berry et al. (2001) report reasonable internal consistency $(\alpha=.73$ and .76 across two studies) and 8-week stability $(r=.69)$ for the TNTF.

\section{The Present Research}

The goal of the present research was to create a brief, coherent measure of dispositional forgiveness that does not take on the conceptual baggage of other constructs and to relate this measure to depression, an important index of mental health. To this end, a four-item measure, the Tendency to Forgive Scale (TTF), was created (see the appendix for a list of the items of the TTF) to capture individual differences in the tendency either to let go of one's offense experiences or hold on to them. Although four items might seem like too few to measure adequately something as complex as forgiveness, the aim of this measure was not to capture the process of forgiveness (how or why it occurs), only individual differences in its outcome (the extent to which it typically occurs).

Preliminary data (Brown, 2000) revealed that responses to the TTF were both internally consistent $(\alpha=$ .82 ) and reliable over time (8-week test-retest $r=.71, N=$ 40). In the largest sample studied to date, including 567 undergraduates (Brown, 2002), the TTF was positively correlated with the Rosenberg Self-Esteem Scale (Rosenberg, 1965), $r=.31$, and negatively correlated with trait anger (Spielberger, Jacobs, Russell, \& Crane, 1983), $r=-.44$, all $p s<.05$. In this sample, men $(M=3.35)$ scored significantly higher than women $(M=3.11)$ on the TTF, although the size of this difference was rather small $(d=.21)$. Scores on the TTF also were correlated modestly with the social desirability subscale of the Eysenck Personality Inventory, $r=.25$ (Eysenck \& Eysenck, 1964). ${ }^{1}$

The purpose of the present research was to examine further the properties of the TTF, with specific focus on its predictive utility, an element that has remained relatively absent in previous work on dispositional forgiveness. Study 1 examined the convergence between individuals' self-reported tendency to forgive and ratings made by a romantic partner. Study 2 investigated the ability of the TTF to predict the accessibility of past offense experiences. Previous researchers and theorists have suggested that forgiveness for specific offenses could facilitate mental and even physical health (e.g., Thoresen, Harris, \& Luskin, 2000), and data from intervention studies offer some support for this contention with regard to depression and anxiety (Freedman \& Enright, 1996). If this is true, then individuals who tend to forgive might be expected to be lower in depression than those who do not tend to forgive. Study 3 examined this hypothesis and empirically distinguished dispositional forgiveness from attitudes about forgiveness and from dispositional vengeance. Finally, Study 4 provided additional discriminant and convergent validity evidence for the TTF in terms of its relations to Berry et al.'s (2001) measure of dispositional forgiveness, a 
measure of dispositional empathy, and the "Big Five" personality dimensions.

\section{STUDY 1: CONVERGENCE WITH PARTNER RATINGS}

As with all self-report measures of personality, determining the validity of an individual's self-assessment of his or her tendency to forgive is an important step in establishing the scale's usefulness. To date, no researchers other than Berry et al. (2001) have tested the convergence between self-reports and observer ratings on previous measures of dispositional forgiveness. In one study with 26 couples (most of whom were dating but some of whom were married), Berry et al. found that self- and partner-ratings were significantly correlated, $r=.60$. Unfortunately, Berry et al. treated the 26 couples as individuals, each of whom provided both a rating of self and a rating of his or her partner. By ignoring the statistical dependence of these paired ratings, Berry et al. may have inflated the estimate of self-other convergence for their measure. Because they did not report the extent to which partners' self-ratings correlated within each couple, the degree of this potential inflation cannot be ascertained. In Study 1, this self-other convergence also was examined among dating couples. To avoid the potential problem of statistical dependence between the self-reports of couple members, each of whom validated the other's self-reports in this study, the convergence between self and partner ratings was examined separately for men and women.

\section{Method}

Participants. The study included 47 dating couples who were recruited from a small, liberal arts college in New England. All participants volunteered to complete a battery of questionnaires as part of a data gathering and analysis project in an introductory statistics course. All couples were heterosexual. The mean age of participants was 20 years and the mean length of relationship was 55 weeks.

Materials and procedure. As part of a large battery of questions, ranging from typical levels of alcohol use to cleanliness habits, participants rated both themselves and their partner on the TTF. As mentioned already, the TTF is a simple, four-item scale designed to assess the extent to which individuals typically experience or engage in forgiveness when they have been wronged by others (see the appendix). Participants rate the extent to which they agree with each of the items on the TTF using Likert-type scales anchored by 1 (strongly disagree) and 7 (strongly agree). Items 2 and 3 are reverse scored. Thus, higher scores on the TTF indicate a greater tendency to forgive, conceptualized as an absence of rumination and a speedy recovery from the negative emotions and cognitions that often accompany the experience of perceiving mistreatment. For the partner ratings in this study, all first-person pronouns on the TTF were replaced with the phrase "my partner." In addition, all participants rated the degree of conflict they experience with their partner by reporting how often they fight and how often they experience disagreements, also on 7 point scales (on which $1=$ never and $7=$ often $)$.

\section{Results and Discussion}

The mean self-ratings of women $(M=3.73)$ and men $(M=3.76)$ did not differ significantly in this study. However, women did, on average, rate their male partners $(M=4.36)$ as being significantly higher in forgiveness than they rated themselves, as demonstrated by a pairedsamples $t$ test, $t(46)=3.01, p<.01$. In contrast, the mean rating given by men of their female partners $(M=3.75)$ was almost exactly equal to the mean rating that women gave themselves. The internal reliability estimates for both the self and partner versions of the TTF were reasonably high $(\alpha=.75$ and .82 for self and partner versions, respectively).

Because, as Kenny (1995) has noted, similarity between members of a dyad can inflate measures of selfother agreement, I next determined the degree of similarity between couple members' self-ratings. The correlation between women's and men's self-ratings on the TTF was low, $r(45)=-.11$, and nonsignificant, well below the $+/-.30$ threshold suggested by Kenny (1995) for assuming dyadic independence for the calculation of self-other convergence.

However, given the slight discrepancy between mean self-ratings and partner ratings for men and women, it seemed plausible that self-other agreement might differ as a function of the gender of individuals making the ratings. Thus, to examine self-other convergence in this sample, I computed the correlation between self-reports and partner ratings separately for men and women. These correlations were very similar, $r(45)=.46$ for female targets and $r(45)=.38$ for male targets, $p s<.02$, and they revealed that respondents' self-ratings agreed with their partners' ratings of them.

Do people's scores on the TTF predict their tendency to experience conflict in their dating relationships? Data from these participants suggest not. Although respondents showed high intracouple agreement in the extent to which they reported experiencing conflict with one another $-r \mathrm{~s}=.71$ and .68 for having "fights" and "disagreements," respectively-these reports of conflict were not significantly correlated with individuals' scores (or their partners' ratings of them) on the TTF, $r s<-.16$, ns. Thus, highly forgiving people might "get over" the wrongs done to them after the fact, but, at least in their dating relationships, they do not appear to experience 
significantly less conflict to begin with than do less forgiving people.

From these data, it appears that participants' selfassessments of their tendency to forgive were corroborated by the assessments of their romantic partners, who should, in theory, have many opportunities to observe their typical degree of forgiveness "in vivo." In comparison, Watson, Hubbard, and Wiese (2000) have recently demonstrated average levels of convergence between dating partners on the subscales of the Big Five personality dimensions at $r=.47$. These authors further showed, however, that self-other convergence tends to be much lower for characteristics that are less overtly manifested or "visible," such as affective states, than for characteristics that are more overt. Because the items of the TTF refer to the internal states of a target, the level of agreement between partners in the current study appears to offer strong support for the validity of self-reports on the TTF, at least relative to other, well-established individual differences. What sorts of "external" cues or manifestations of these internal states are being used by partners as the bases for their assessments cannot be directly determined from this study but must await further research.

\section{STUDY 2: KEEPING A RECORD OF WRONGS}

Having demonstrated that self-ratings on the TTF converge with ratings made by knowledgeable others, I next turn to the predictive validity of the TTF. An examination of the content of the TTF shows that individuals with high scores on this scale are claiming to put offense experiences out of their minds, avoiding hostile rumination and grudge holding. If these claims are true, we should expect that when called on to recall past offenses, forgiving individuals should experience some difficulty doing so. If they do, indeed, leave these offenses in the past and truly "get over" them, then these offenses should be less cognitively accessible for them than for individuals with low scores on the TTF. Thus, higher TTF scores should be associated with fewer recalled offenses under strict time constraints. This was the primary prediction of Study 2.

Study 1 suggested that people with high scores on the TTF do not necessarily experience less frequent conflict with others. However, it seems reasonable to question whether individuals with high scores on the TTF might only appear to be highly forgiving individuals because they tend not to experience offenses in the same way that others do. For example, perhaps more forgiving individuals do not feel the pain of slights, insults, or betrayals as keenly as do less forgiving individuals. Such a relation between the subjective hurtfulness of offenses and scores on the TTF could possibly explain why high scorers might not be able to recall as many offenses under time constraint, but this line of reasoning would suggest that the lower availability of offense experiences may be due in part to the weaker emotional impact of these experiences for high scorers, which might point to some other disposition as the underlying cause of any link between TTF scores and number of recalled offenses. Thus, Study 2 also examined the relation between scores on the TTF and ratings of the perceived hurtfulness of each recalled offense experience.

Method

Participants. The study included 69 undergraduates (48 women, 21 men) taking an introductory psychology course at a small, liberal arts college in the Northeast who participated in this study for credit toward a course research requirement. The mean age of participants was 19 years. Forty-one participants were Caucasian, 4 were Black, 7 were Hispanic, 2 were Asian, and 15 were Other (or did not indicate their race/ethnicity).

Materials and procedure. This study took place over two sessions, separated by 7 to 10 days. At the initial session, participants completed the TTF in small groups as part of a battery of questionnaires being pretested for several unrelated studies. At the second session, participants were first instructed to list, briefly, as many interpersonal offenses as they could think of, regardless of whether they felt they were "over" these offenses. Instructions indicated that the offending parties could be friends, strangers, family members, or significant others, and the offenses could be actions or inactions. As an exploratory variable, half of the participants were given $2 \mathrm{~min}$ to recall these offenses and the remaining participants were given $4 \mathrm{~min}$ to recall. When participants had listed as many offenses as they could recall, they then went back, without time constraint, and rated how hurtful each recalled offense had been at the time that it had occurred. Participants made these ratings on a 9-point scale anchored with not at all hurtful (1) and very hurtful (9). Finally, participants indicated whether the person responsible for each recalled offense had ever apologized (4 participants failed to provide this information for any of the offenses listed).

Results

On average, participants recalled 4.03 offenses $(S D=$ 1.63 , range $=1-9$ ), and these offenses were rated as being moderately hurtful on average $(M=5.63, S D=1.34)$. Participants also reported that they had received an apology for only about $25 \%$ of the offenses listed. Indeed, slightly more than $26 \%$ of the participants reported that they had not received an apology for any of the offenses they listed. In contrast to Study 1, women scored slightly lower $(M=3.29)$ than did men $(M=3.74)$ on the TTF in this sample, $F(1,67)=2.74, p=.10$. Women also rated the average recalled offense as being only slightly more hurt- 
TABLE 1: Zero-order Correlations and Descriptive Statistics for Variables in Study 2

\begin{tabular}{lcccc}
\hline & TTF & Recall & Hurtfulness & Apology \\
\hline Recall & $-.25^{*}$ & - & & \\
Hurtfulness & $-.31^{*}$ & .14 & - & \\
Apology & -.12 & .08 & -.07 & - \\
Means & & & & \\
$\quad$ Men & 3.74 & 3.86 & 5.29 & $24 \%$ \\
$N$ & 21 & 21 & 21 & 20 \\
Women & 3.29 & 4.10 & 5.78 & $26 \%$ \\
$N$ & 48 & 48 & 48 & 45 \\
\hline
\end{tabular}

NOTE: TTF $=$ Tendency to Forgive Scale; recall $=$ number of offenses recalled; hurtfulness = average hurtfulness of all offenses recalled; apology $=$ percentage of all recalled offenses for which participants reported having received an apology.

$* p<.05$.

ful $(M=5.78)$ than did men $(M=5.29), F(1,67)=1.97$, $p>.15$. However, women did not recall any more offenses than did men $(p>.50)$. Not surprisingly, participants who were given only 2 min recalled somewhat fewer offenses $(M=3.72)$ than did participants who were given 4 min to recall $(M=4.36), F(1,67)=2.75, p=.10$.

As shown in Table 1, high scores on the TTF were related to fewer recalled offenses, $r=-.25, p<.05$. TTF scores also were negatively correlated with hurtfulness ratings, $r=-.31, p<.01$. This latter relation allows for the possibility that the perceived severity of the reported offenses might confound the relation between TTF scores and recall. However, hurtfulness did not correlate significantly with offense recall, $r=.14, p>.25$. Nonetheless, to allow an assessment of the unique contribution of TTF scores to the prediction of offense recall, a simultaneous multiple regression analysis was conducted that included TTF scores and hurtfulness ratings as predictors of recall, controlling for amount of time constraint. In this regression, only TTF scores were at all predictive of recall, $\beta=-.24, p=.058$; hurtfulness ratings were not even close, $\beta=.06, t<1$. The percentage of each participant's offenses that had received an apology also was not predictive of the number of offenses recalled, either by itself or when included in the regression analysis with TTF scores, hurtfulness, and time constraint, $\beta<.06, t<$ 1. Finally, no moderation of the TTF-recall relation was produced by either manipulated time constraint or hurtfulness ratings (all $t \mathrm{~s}<1$ ).

\section{Discussion}

Study 2 showed that scores on the TTF predicted the number of offense experiences that individuals could call to mind in a short amount of time. Combining these results with those of Study 1, it appears that dispositionally forgiving individuals do not experience less frequent conflict with others, but they do seem to get over their conflict experiences more easily than do nonfor- giving individuals. These results complement previous results obtained by McCullough et al. (1998) with regard to ruminative thoughts about a particular offense, as well as the negative correlation reported by Berry et al. (2001) between scores on their dispositional forgiveness scale and a measure of aggressive rumination.

Results from Study 2 not only supported the hypothesis that high scores on the TTF would predict less offense accessibility but also supported the prediction that the TTF would do so independently of participants' ratings of the hurtfulness of each offense. Of interest, scores on the TTF were negatively correlated with these hurtfulness ratings, suggesting that perhaps the inability to recall as many offenses might be due to high TTF scorers having less intense emotions attached to these memories. However, the hurtfulness of these offenses was not significantly related to the number of offenses recalled. Thus, if another personality dimension underlies the degree of hurt experienced by victims, it does not seem from these data that such a personality dimension could account for the association between the TTF and offense accessibility. But perhaps forgiving individuals tend to experience a waning of offense-related negative affect over time. Such diminished negativity could, in turn, influence their retrospective accounts of how hurtful offenses were at the time that they occurred, thus reducing an otherwise significant relationship between hurtfulness and recall. Although such a reduction of negative affect might occur, it would not seem to account for the inability of forgiving individuals to recall past offense experiences, given the nonsignificant relation between hurtfulness ratings and recall. Furthermore, scores on the TTF did not interact with hurtfulness ratings to predict recall; thus, the degree of reported hurt associated with the offenses that participants recalled was not related to the number of recalled offenses among either forgiving or unforgiving individuals.

Although the correlation between scores on the TTF and number of recalled offenses was very modest in this study, at present, these data represent the first non-selfassessment correlates of a dispositional measure of forgiveness. The offense recall measure is, admittedly, a crude index of offense accessibility and is potentially influenced by a host of variables, including writing speed and performance under time constraints. This very roughness, however, makes its use as a criterion measure a conservative test of the predictive validity of the TTF. An important step for future research will be to relate scores on the TTF to more overt, behavioral indices of offense-specific forgiveness to substantiate these findings. Indeed, such behavioral data remain almost completely absent in research on forgiveness, whether at the dispositional, offense-specific, or dyadic level (McCullough, Hoyt, \& Rachal, 2000). 
STUDY 3: DISPOSITIONAL FORGIVENESS, VENGEANCE, AND ATTITUDES TOWARD FORGIVENESS

Studies 1 and 2 support the validity and predictive utility of the TTF. These results, similar to those presented by Berry et al. (2001) with the TNTF, are predicated on the notion that a disposition to forgive can be captured by a unidimensional measure. Indeed, as noted in the introduction to this article, the simplicity of the TTF is considered a conceptual benefit of this measure, in contrast to previous measures such as those of Mauger et al. (1992) and Gorsuch and Hao (1993). These other measures seem to conflate forgiveness with moral/ethical values concerning forgiveness and vengeance, as well as with retaliatory behaviors and even the responses of offenders. Compared to such measures, the relative "purity" of a simple measure such as the TTF seems to be more a strength than a weakness.

Still, none of the data presented so far directly support the contention that the tendency to forgive is distinct from attitudes about forgiveness or from dispositional vengeance. This contention does seem questionable given the likely overlap between attitudes about forgiveness and the enactment of forgiveness, and between unforgiveness and vengeance. Empirically exploring these issues was the primary focus of Study 3. Besides simply relating the tendency to forgive to attitudes about forgiveness and to vengeance seeking, Study 3 also sought to establish the incremental validity of the TTF in predicting mental health independently of these other constructs. Such incremental validity would substantially enhance the argument that these constructs, although related, ought to be distinguished when measuring dispositional forgiveness and assessing its consequences for well-being.

Previous research on the self-concept summarized by Higgins (1987) has demonstrated that people who fall short of realizing their "ideal selves" or their "ought selves" tend to experience various forms of negative affect, from guilt, shame, and self-contempt to disappointment, dissatisfaction, and frustration. Perhaps a reasonable parallel could be made between ideal/ought selves and attitudes about the virtues of forgiveness. ${ }^{2}$ If the tendency to forgive is, in fact, empirically distinct from attitudes toward forgiveness, then some individuals may be low in the tendency to forgive but nonetheless have positive attitudes toward forgiveness. Such individuals would value forgiveness and consider it a moral virtue but not actually be forgiving people themselves. Study 3 investigated whether such individuals might be especially prone to experience depression. Thus, the interaction between the tendency to forgive and attitudes about forgiveness also was examined in this study.

Similarly, Study 3 investigated the possibility that the tendency to forgive might interact with dispositional vengeance. Complementing predictions concerning attitudes toward forgiveness, perhaps individuals who do not forgive but who also do not seek vengeance would be more depressed than individuals who do not forgive but who do seek vengeance. This hypothesis was predicated on the notion that although vengeance seeking might be associated with hostility and dissatisfaction with life (see McCullough et al., 2001), those who fail to forgive might be less depressed if they get back at those who mistreat them than if they do nothing at all. Those who neither forgive nor retaliate when they are wronged might be characterized by the sense of helplessness that previous research has shown to be associated with depression (e.g., Peterson, Maier, \& Seligman, 1993; Peterson \& Seligman, 1984). As with the prediction of an interaction between the tendency to forgive and attitudes toward forgiveness, the possibility of an interaction with vengeance seeking was neither the primary focus nor a necessary result to support the empirical distinction between these constructs. Nonetheless, finding such an interaction would support the distinction between these constructs and bolster the argument that the simplicity of the TTF might be a strength rather than a weakness of the measure.

\section{Method}

Participants. The study included 70 students (32 women, 37 men, 1 unspecified) in an introductory management course at a large, Midwestern university who participated for course credit. The mean age of participants was 22.6 years, with a range of 18 to 41 years old. Participants were predominantly Caucasian (67\%), 17\% were Asian, 4.3\% were African American, 3\% were Native American, $1.4 \%$ were Hispanic, and the remaining $1.4 \%$ did not indicate their ethnicity.

Materials and procedure. Participants completed a large battery of questionnaires (which were counterbalanced in five random orders), including those relevant to the current study. In addition to the TTF, participants also completed a six-item measure of Attitudes Toward Forgiveness (ATF; see the appendix) that was designed specifically for this study. This measure assessed the extent to which participants viewed forgiveness as a virtue or desirable characteristic, regardless of the extent to which they themselves actually practice forgiveness. Thus, all items on this scale are attitudinal; in contrast, the items on the TTF are all "experiential" or "behavioral" in that they only refer to the extent to which individuals actually forgive, whatever they might think of the value of forgiveness.

To assess participants' vengeance attitudes and behaviors, participants completed Stuckless and Goranson's (1992) Vengeance scale. This scale is a 20-item measure with good face validity and psychometric properties, 
TABLE 2: Zero-Order Correlations and Descriptive Statistics for Variables in Study 3

\begin{tabular}{lcccc}
\hline & $T T F$ & ATF & Vengeance & Depression \\
\hline 1. ATF & $.33^{* *}$ & & & \\
2. Vengeance & $-.45^{* * *}$ & $-.57^{* * *}$ & & \\
3. Depression & $-.34^{* *}$ & .09 & .02 & - \\
Means & & & & \\
Men & 3.88 & 4.98 & 3.31 & 32.49 \\
SD & 1.26 & 0.93 & 0.83 & 9.19 \\
Women & 4.01 & 5.26 & 2.88 & 34.78 \\
SD & 1.22 & 0.82 & 0.76 & 8.47 \\
Alpha & .73 & .61 & .86 & .92 \\
\hline
\end{tabular}

NOTE: TTF $=$ Tendency to Forgive Scale; ATF $=$ Attitudes Toward Forgiveness Scale.

$* * p<.01 . * * * p<.001$.

although it does indiscriminantly combine attitudes and behaviors related to vengeance (as well as a single item referring specifically to forgiveness). Example items on the Vengeance scale are "To have a desire for vengeance would make me feel ashamed," "It is important for me to get back at people who have hurt me," and "I don't just get mad-I get even." Finally, participants also completed the Centers for Epidemiological Studies Depression Scale (CESD; Radloff, 1977) to assess recent occurrences of depressed symptoms. On this measure, participants rated the frequency with which they had experienced a variety of symptoms during the past week using a 4-point scale with endpoints labeled rarely or none of the time: less than 1 day (1) and most or all of the time: 5-7 days (4). Example items are "I did not feel like eating; my appetite was poor," "My sleep was restless," and "I felt depressed."

Results

Zero-order relations. All measures demonstrated reasonable internal consistencies, as shown in Table 2. The only significant gender difference that emerged indicated that women scored lower on the Vengeance scale $(M=$ 2.88) than did men $(M=3.31), F(1,67)=5.02, p<.03$. Table 2 displays the zero-order correlations between the primary variables. Supporting the notion that attitudes about forgiveness, vengeance, and the tendency to forgive are distinguishable constructs, Table 2 shows that the TTF was only modestly correlated with ATF and Vengeance. As evidence of the predictive independence of these constructs, only the TTF was significantly related to self-reported symptoms of depression, $r=-.34, p<.01$. An exploratory analysis of gender differences in correlations revealed only a significant difference between the TTF/ATF correlation (which was stronger for men than for women, $p<.05)$. Because gender was not a significant predictor in any of the analyses reported below, it will not be discussed further.
Multiple regression analyses. Regressing depression scores on the TTF, the ATF, Vengeance, and age revealed that the only significant predictor of depression was the TTF, $\beta=-.41, p<.01$. Age was marginally significant, $\beta=$ $-.17, p<.15$. Indeed, controlling for the tendency to forgive, Vengeance was actually negatively related to depression, $\beta=-.10$, although this relation was not statistically significant $(p>.20)$.

In addition to this multiple regression comparing the relative strength of these predictors, two additional regression analyses were performed separately to examine the hypotheses about interactions between the tendency to forgive and attitudes toward forgiveness, and between the tendency to forgive and vengeance seeking. In the first of these analyses, TTF scores and ATF scores were first centered on their respective means before the interaction term was created (Aiken \& West, 1991). Following this, the centered predictor variables were entered along with age and the interaction between TTF and ATF. In this analysis, TTF scores were significantly related to depression, $\beta=-.32, p<.05$. As well, ATF scores and age were not significantly related to depression $(\beta \mathrm{s}=$ .18 and -.16 for ATF and age, respectively, $p s<.165)$. But as expected, the TTF/ATF interaction was significant, $\beta=-.23, p=.05$. Simple slopes tests (performed at $+/-1$ $S D$ of the TTF) revealed that at high levels of the TTF, the ATF was not significantly related to depression, $\beta=-.06$, $n s$. However, at low levels of the TTF, the ATF was positively related to depression, $\beta=.41, p<.05$. Thus, as predicted, individuals who were not forgiving but who expressed positive attitudes toward forgiveness reported more depressed symptoms than individuals who were not forgiving but also did not value forgiveness. This interaction between the TTF and the ATF is displayed in Figure 1. Controlling for Vengeance did not change any of these patterns.

A separate analysis regressed depression on age, the TTF, Vengeance, and the TTF/Vengeance interaction (after first centering each continuous variable on its mean). This analysis revealed that the TTF was significantly related to depression, $\beta=-.33, p<.05$, but Vengeance was not, $\beta=-.16, p>.20$. Age was also not a significant predictor, $\beta=-.17, p<.15$. However, the TTF also interacted with Vengeance, $\beta=.23, p<.05$. Simple slope tests $($ at $+/-1 S D$ of the TTF) revealed that at high levels of the TTF, Vengeance was not significantly associated with depression, $\beta=.08$, ns; however, at low levels of the TTF, Vengeance was negatively associated with depression, $\beta=-.40, p<.05$. Thus, nonforgiving individuals who also did not tend to retaliate against those who wronged them were more depressed than those who did tend to retaliate. In contrast, vengeance seeking had only a small, nonsignificant relation with depression among forgiving individuals. This interaction is displayed in Fig- 


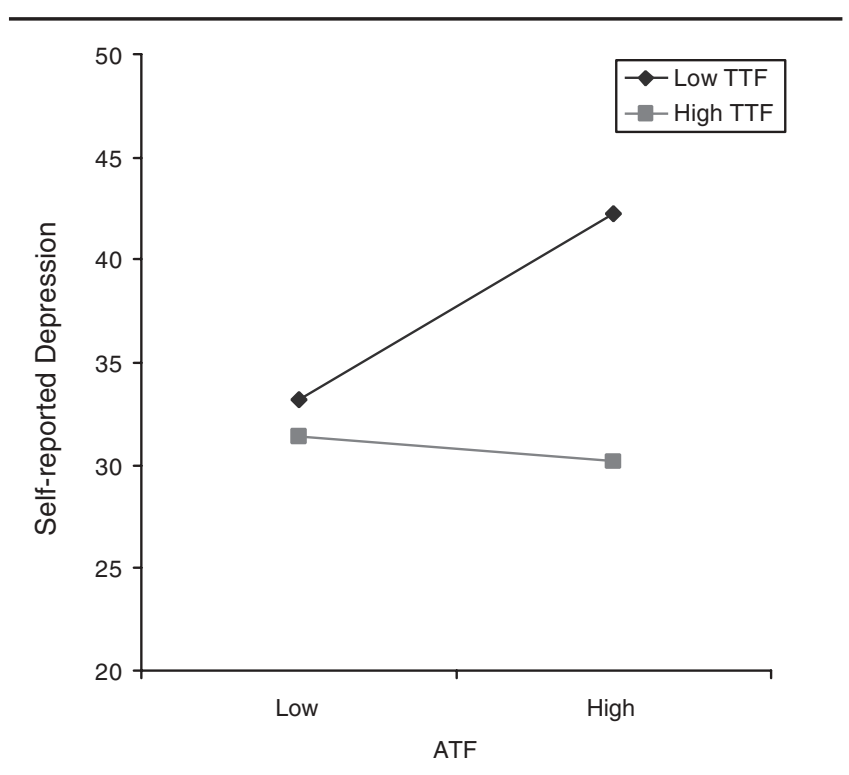

Figure 1 Self-reported depression levels as a function of ATF and TTF scores.

NOTE: ATF $=$ Attitudes Toward Forgiveness Scale; TTF $=$ Tendency to Forgive Scale. Low and high values on both the TTF and the ATF were calculated at $+/-1 S D$ of each variable.

ure 2. Controlling these analyses for ATF scores did not change any of these patterns.

\section{Discussion}

The results of Study 3 support the contention that when measuring individual differences in the tendency to forgive, one must be careful not to conflate forgiveness with attitudes about forgiveness or with dispositional vengeance. Although these constructs are all related, they are not synonymous. An individual could believe that forgiveness is a virtuous act without actually being a forgiving person. Likewise, even though being a vengeful person is clearly incompatible with being a forgiving person, it is not necessarily true that those who are not vengeful are necessarily forgiving. Such individuals might simply abhor vengeance-seeking enough to control their impulse to retaliate against those who wrong them, even while retaining a grudge. Alternatively, perhaps some nonvengeful individuals feel powerless to take action against their offenders; thus, although they do not forgive, they also do not take revenge frequently.

Study 3 further demonstrates the distinctions between dispositional forgiveness, attitudes toward forgiveness, and dispositional vengeance by showing evidence of their interactions in predicting depression. Across every analysis, scores on the TTF were negatively related to depression, which complements the results of Study 2 on forgiveness and offense accessibility. In addition, Study 3 showed that nonforgiving individuals were more likely to be depressed if they highly valued forgiveness. As noted already, this finding is analogous to Hig-

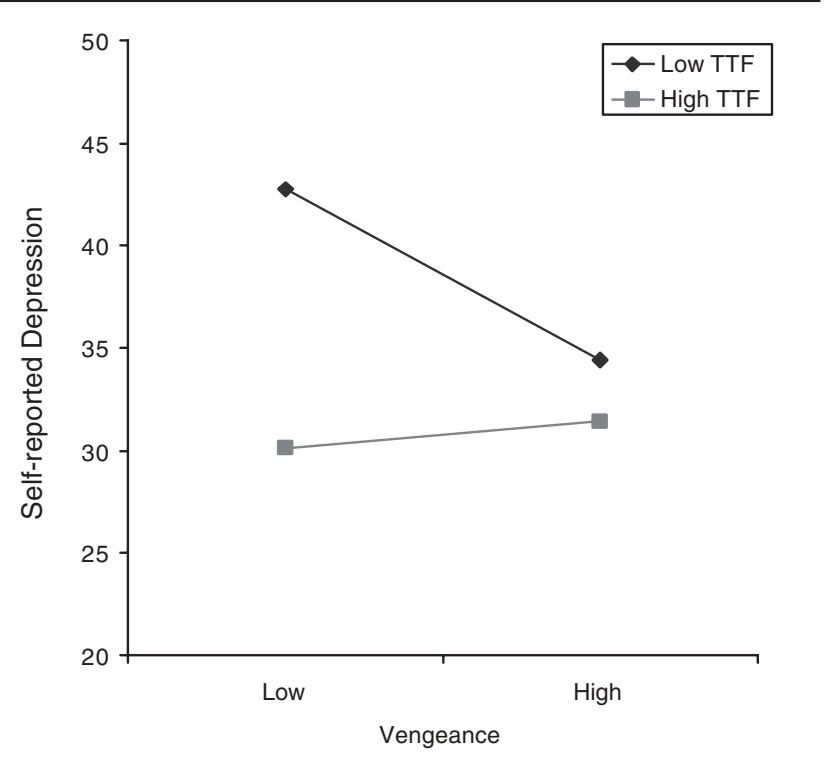

Figure 2 Self-reported depression levels as a function of Vengeance and TTF scores.

NOTE: TTF $=$ Tendency to Forgive Scale. Low and high values on both the TTF and the Vengeance scale were calculated at $+/-1 S D$ of each variable.

gins's (1987) discussion of self-discrepancies. His work has shown that individuals who fail to be the person they believe is ideal, or the person they believe they ought to be, tend to experience a host of negative affective states. Likewise, Study 3 showed that individuals with low scores on the TTF were higher in depression if they were also low in vengeance seeking. It should be noted, however, that these results are purely correlational and, as such, the causal directions implied by the hypotheses of Study 3 cannot be strongly inferred. Perhaps individuals who are highly depressed and low in forgiveness enhance the importance of forgiveness in a self-punitive manner. After all, individuals low in forgiveness do tend to be low in self-esteem (Brown, 2002). A similar alternative perspective could be taken with regard to the forgiveness/ vengeance interaction. Perhaps individuals who are low in forgiveness and high in depression simply fail to seek vengeance because they feel they deserve the wrongs done to them. The results reported in Study 3 may be consistent with a number of alternative interpretations besides the one that led to this study's predictions. ${ }^{3}$ Nonetheless, these results do support the distinction between forgiveness tendencies, forgiveness attitudes, and vengeance seeking, no matter what the precise causal path is between these constructs and depression.

\section{STUDY 4: CONVERGENT AND DISCRIMINANT VALIDITY}

The three studies reported so far have demonstrated reasonable evidence for the predictive validity of the TTF, as well as its discriminant validity with reference to 
attitudes about forgiveness and vengeance. Study 4 was designed to extend the convergent and discriminant validity evidence by examining relations between scores on the TTF, the ATF, and the Vengeance scale (Stuckless \& Goranson, 1992) along with scores on Berry et al.'s (2001) TNTF, a measure of dispositional empathy, and the dimensions of the Big Five personality taxonomy.

Scores on the TTF were expected to be moderately correlated with the ATF and Vengeance scale, as in Study 3, and with Berry et al.'s (2001) TNTF. Because being able to take another person's perspective, especially in conflict situations, should facilitate forgiveness (see Fincham, 2000; McCullough et al., 1998; McCullough, Worthington, \& Rachal, 1997), it also was predicted that dispositional forgiveness would be positively correlated with dispositional perspective taking, as measured by the perspective taking subscale of Davis's (1983) Interpersonal Reactivity Inventory (IRI), a multi-dimensional measure of dispositional empathy. A second factor in this scale is empathic concern, which assesses the extent to which respondents feel emotionally moved by the distress of others. No predictions were made a priori about this second dimension of empathy because one could reason that empathic concern could be associated with either higher or lower forgiveness. ${ }^{4}$ The TTF also was expected to be positively correlated with the Big Five factor of agreeableness and negatively with neuroticism, as suggested by McCullough (2000) and Emmons (2000). No associations between the TTF and the remaining Big Five dimensions (i.e., conscientiousness, openness, and extraversion) were predicted.

\section{Method}

Participants. The study included 101 undergraduates (64 women, 37 men) at a large, Midwestern university who participated in this study for course credit toward a research requirement in an introductory psychology course.

Materials and procedure. Participants completed, in random order, five measures: the TTF, the ATF, the Vengeance scale, the TNTF, two relevant subscales from Davis's (1983) Interpersonal Reactivity Inventory (IRI), and the Big Five Inventory (BFI) (John, Donahue, \& Kentle, 1992). The first three measures have already been described in some detail. As noted in the introduction, the TNTF presents participants with five hypothetical offense scenarios. Following each scenario, respondents indicate the extent to which they believe they would forgive the offender, using a single, 5-point scale anchored with definitely not forgive (1) and definitely forgive (5). On the TNTF, dispositional forgiveness scores are computed as an average of participants' responses to the five scenarios. The two dimensions of Davis's (1983) IRI that seem to be most potentially relevant to forgiveness-perspective taking and empathic concern-are measured by 14 items to which respondents indicate their agreement on 5-point Likert-type scales, anchored with strongly disagree (1) and strongly agree (5). Examples of empathic concern items are "I often have tender, concerned feelings for people less fortunate than me" and "I would describe myself as a pretty softhearted person." Examples of perspective taking items are "I try to look at everybody's side of a disagreement before I make a decision" and "Before criticizing somebody, I try to imagine how I would feel if I were in their place.” Davis (1983; Davis, Hull, Young, \& Warren, 1987) reports that these subscales are internally consistent and demonstrate discriminant validity with regard to empathic accuracy and to various cognitive and emotional reactions to empathy-relevant stimuli. The BFI is a well-validated measure designed to tap the five personality dimensions of agreeableness, neuroticism, conscientiousness, openness to experience, and extraversion. Respondents indicated the extent to which they believed that the 44 characteristics of the BFI described them, using a response scale identical to that described for the IRI.John et al. (1992) report that the subscales of the BFI are reasonably internally reliable and self-ratings correlate significantly with peer ratings (although the degree of this self-other convergence varies substantially across the subscales). All measures used in Study 4 were adequately reliable, with internal consistency estimates ranging from a low of . 71 for the ATF to a high of .88 for extraversion.

\section{Results and Discussion}

As shown in Table 3, the TTF was significantly related to both the ATF $(r=.37)$ and the Vengeance scale $(r=$ -.39), as in Study 3. In addition, scores on the TTF were significantly related to scores on Berry et al.'s (2001) measure of dispositional forgiveness, the TNTF $(r=.39)$. Thus, the TTF demonstrated consistent convergence with related measures. Still, these correlations were not so high as to make the TTF redundant with them. Although the modesty of this overlap was to be expected in the case of the ATF and the Vengeance scale, which operationalize distinguishable constructs, the relatively low correlation between the TTF and the TNTF is more striking, given that these measures are ostensibly assessing the same construct.

The patterns of association between these two forgiveness indices and the facets of the BFI also demonstrate convergence and divergence between these measures. Neither measure was significantly correlated with conscientiousness or openness (all is $<.11$ ). As expected, the TTF was positively correlated with agreeableness $(r=$ $.43)$, negatively correlated with neuroticism $(r=-.39)$, and virtually uncorrelated with extroversion $(r=.08)$. 
TABLE 3: Comparisons of Zero-Order Correlates With the TTF and the TNTF in Study 4

\begin{tabular}{lcc}
\hline Predictor Variables & TTF & TNTF \\
\hline Attitudes toward forgiveness & $.37 * *$ & $.51 * *$ \\
Vengeance & $-.39 * *$ & $-.38^{* *}$ \\
Empathic concern & .01 & .16 \\
Perspective taking & $.29 * *$ & $.40^{* *}$ \\
Conscientiousness & .04 & .04 \\
Neuroticism & $-.39 * *$ & -.10 \\
Agreeableness & $.43 * *$ & $.27 * *$ \\
Openness & .07 & .11 \\
Extraversion & .08 & $.20 *$ \\
TTF & - & $.39 * *$ \\
TNTF & $.39 * *$ & - \\
\hline
\end{tabular}

NOTE $:$ TTF $=$ Tendency to Forgive Scale. TNTF $=$ Transgression Narrative Test of Forgivingness. Cronbach's alpha was . 76 for the TTF and .82 for the TNTF.

$* p<.05 . * * p<.01$.

These associations with agreeableness and neuroticism are in concordance with theoretically derived speculations by McCullough (2000) and Emmons (2000) about the nature of the forgiving personality. In contrast, although the TNTF also was correlated with agreeableness $(r=.27)$, it was not significantly correlated with neuroticism $(r=-.10)$ but was positively correlated with extroversion $(r=.20)$. These results with the TNTF are generally consistent with those reported by Berry et al. (2001) with the exception of the nonsignificant relation to neuroticism. In addition to these correlations, men scored nonsignificantly higher on the TTF than did women $(M \mathrm{~s}=4.14$ and 3.84 for men and women, respectively), $F(1,99)=2.10$, $n s$, whereas women scored higher on the TNTF than did men $(M \mathrm{~s}=15.14$ and 13.51 for women and men, respectively), $F(1,99)=3.80, p=.05$. It seems clear from these results that, although convergent, the TTF and the TNTF are not isomorphic measures of the forgiving disposition.

To examine further the similarities and differences between the TTF and the TNTF, simultaneous multiple regressions were performed using every predictor variable to account for variance in the TTF and the TNTF (separately). These analyses revealed strikingly different patterns. Whereas the only independent predictors of the TTF were agreeableness $(\beta=.29, p<.05)$ and neuroticism $(\beta=-.27, p<.05)$, the only independent predictors of the TNTF were the ATF $(\beta=.45, p<.01)$ and perspective taking $(\beta=.28, p<.01)$. Thus, scores on the TTF seem to have their strongest associations with two theoretically relevant components of personality, whereas scores on the TNTF seem to have their strongest associations with individuals' beliefs in the value of forgiveness and their tendency to take others' perspectives (the "cognitive" component of empathy, see Davis,
1983). It is noteworthy that adding the TNTF as a predictor of TTF scores, and adding the TTF as a predictor of TNTF scores, did not meaningfully change the significance of any of the other predictors in these regression models, although both the TNTF and the TTF were independently significant predictors of one another $(\beta \mathrm{s}>.23, p \mathrm{~s}<.05)$.

\section{GENERAL DISCUSSION}

The results of these four studies provide preliminary evidence in support of the utility of the TTF as a measure of dispositional forgiveness. Not only do individuals' selfreports of their tendency to forgive agree with ratings made of them by their romantic partners (Study 1) but these ratings also predict the accessibility of past offense experiences (Study 2). The latter finding complements the inverse relation between forgiveness and depression (Study 3) insofar as heightened accessibility of negative experiences has been associated with depression in previous research (Greenberg, 1995; Holman \& Silver, 1996; Lyubomirsky \& Nolen-Hoeksema, 1993, 1995; Nolen-Hoeksema, 1991).

In addition to showing the negative association between forgiveness and depression, Study 3 also demonstrated the importance of distinguishing between the tendency to forgive, attitudes toward forgiveness, and dispositional vengeance. Of these three, only the tendency to forgive was significantly (negatively) correlated with depression. Indeed, the correlation between vengeance and depression was actually positive, albeit nonsignificant. Given this latter relation, it should not be surprising that Mauger et al. (1992) reported such a small correlation $(r=.16)$ between self-reported depression and their Forgiveness of Others Scale, which conflates the forgiveness disposition with vengeance attitudes. Further evidence for the importance of distinguishing between these forgiveness-related constructs was that the TTF interacted with forgiveness attitudes and with vengeance to predict depression. These interactions revealed that individuals were less depressed if they were high in the tendency to forgive. However, if they were low in the tendency to forgive, then they were better off also having less positive attitudes about the value of forgiveness or being high in vengeance.

The inverse relation between the TTF and depression complements the results reported by Berry et al. (2001) showing that dispositional forgiveness (assessed via the TNTF) was negatively correlated with anger and hostility. Together, such associations support previous speculations that forgiveness might be associated with mental health and well-being (e.g., McCullough, 2000; Thoresen, Harris, \& Luskin, 2000). Even so, we must view all such concurrent correlations with caution because they cannot be taken as direct evidence that 
dispositional forgiveness is causally linked with any of these affective states. Although experimental evidence offers some support for such a causal link (e.g., Freedman \& Enright, 1996), longitudinal studies that track changes in depression, anger, or anxiety over time would strengthen the data reported here. It certainly seems plausible, too, that depression, anxiety, and anger could themselves inhibit individuals from forgiving, which suggests possible reciprocal causal relations between forgiveness and these variables.

Future research on dispositional forgiveness would do well to include both the TTF and Berry et al.'s (2001) TNTF because the results of Study 4 suggest that these measures are not entirely equivalent. Differences in the response formats of the TTF and TNTF might explain some of this difference. Whereas the TTF requires respondents to report on the extent to which they have forgiven offenses in the past, the TNTF demands that they imagine how they might respond to hypothetical offenses. It may be that respondents do the latter by considering how they have actually responded to past offenses and integrating these previous experiences with their desires to be forgiving people (their forgiveness attitudes) and their beliefs about their abilities to take others' perspectives. Although the TTF and the TNTF seem to have partially overlapping profiles with respect to the Big Five personality dimensions, the TNTF appears to have a more substantial forgiveness ideal component, as measured by the ATF, that is independent of respondents' self-reported tendency to forgive. Without more research comparing these measures of dispositional forgiveness, hypotheses regarding their differential utility for predicting mental health and social interactions can only be speculative at this time. For now, though, the TTF appears to be a reasonably sound and operationally "pure" measure of the forgiveness disposition. These qualities make it a potentially valuable instrument for future studies on the development and consequences of trait forgiveness.

\section{APPENDIX}

Items of the Tendency to Forgive Scale and the Attitudes Toward Forgiveness Scale

\section{Tendency to Forgive (TTF)}

1. "I tend to get over it quickly when someone hurts my feelings."

2. "If someone wrongs me, I often think about it a lot afterward." (reversed)

3. "I have a tendency to harbor grudges." (reversed)

4. "When people wrong me, my approach is just to forgive and forget."

\section{Attitudes Toward Forgiveness (ATF)}

1. "I believe that forgiveness is a moral virtue."

2. "Justice is more important than mercy." (reversed)

3. "It is admirable to be a forgiving person."

4. "I have no problem at all with people staying mad at those who hurt them." (reversed)

5. "Forgiveness is a sign of weakness." (reversed)

6. "People should work harder than they do to let go of the wrongs they have suffered."

NOTE: Responses to both scales are given on 7-point Likert-type scales anchored with strongly disagree (1) and strongly agree (7).

\section{NOTES}

1. Because, as Diener, Sandvik, Pavot, and Gallagher (1991) have noted, substantial variance in what is captured by typical "social desirability" scales may be an element of basic personality related to general well-being, it is not surprising that such a scale would be somewhat correlated with a measure of dispositional forgiveness.

2. Whether the "ideal" or "ought" category better characterizes the construct captured by the Attitudes Toward Forgiveness Scale is debatable. Further empirical investigations designed to answer this question would be necessary to address this question. It may be instructive, however, that discrepancies between people's actual selves and their ideal selves are more strongly associated with depression than discrepancies between actual and ought selves, according to Higgins (1987). Thus, if the tendency to forgive interacts with attitudes toward forgiveness to predict depression, this might suggest that these attitudes toward forgiveness are best thought of as "forgiveness ideals."

3. I am grateful to an anonymous reviewer for highlighting these interesting alternative perspectives on the results of Study 3.

4. Although people high in empathic concern might feel enhanced empathy for the possible distress of their transgressors, who could conceivably be suffering over the guilt of their misdeeds, empathic concern also might reflect a greater interpersonal sensitivity that could make such individuals especially prone to experiencing their own distress when they are mistreated by others. Indeed, empathic concern scores are highly correlated with general emotionality (Davis, 1983). Thus, empathic concern could either be associated with higher or lower forgiveness, both at the state and traits levels.

\section{REFERENCES}

Aiken, L. S., \& West, S. G. (1991). Multiple regression: Testing and interpreting interactions. Newbury Park, CA: Sage.

Berry, J. W., Worthington, E. L., Jr., Parrott, L., O'Connor, L. E., \& Wade, N. G. (2001). Dispositional forgivingness: Development and construct validity of the transgression narrative test of forgivingness (TNTF). Personality and Social Psychology Bulletin, 27, 12771290.

Brown, R. P. (2000). Unpublished raw data, The University of Oklahoma.

Brown, R. P. (2002). Unpublished raw data, The University of Oklahoma.

Davis, M. H. (1983). Measuring individual differences in empathy: Evidence for a multidimensional approach. Journal of Personality and Social Psychology, 44, 113-126.

Davis, M. H., Hull, J. G., Young, R. D., \& Warren, G. G. (1987). Emotional reactions to dramatic film stimuli: The influence of cognitive and emotional empathy. Journal of Personality and Social Psychology, 52, 126-133.

Diener, E., Sandvik, E., Pavot, W., \& Gallagher, D. (1991). Response artifacts in the measurement of subjective well-being. Social Indicators Research, 24, 35-56.

Emmons, R. A. (2000). Personality and forgiveness. In M. E. McCullough, K. I. Pargament, \& C. E. Thoresen (Eds.), Forgiveness: Theory, research, and practice (pp. 156-175). New York: Guilford. 
Enright, R. D., Freedman, S., \& Rique, J. (1998). The psychology of interpersonal forgiveness. In R. D. Enright \& J. North (Eds.), Exploring forgiveness (pp. 46-62). Madison: The University of Wisconsin Press.

Enright, R. D., \& The Human Development Study Group. (1991). The moral development of forgiveness. In W. Kurtines \& J. Gewirtz (Eds.), Handbook of moral behavior and development (Vol. 1, pp. 123-152). Hillsdale, NJ: Lawrence Erlbaum.

Eysenck, H. J., \& Eysenck, S. B. G. (1964). The manual of the Eysenck Personality Inventory. London: University of London Press.

Fincham, F. D. (2000). The kiss of the porcupines: From attributing responsibility to forgiving. Personal Relationships, 7, 1-23.

Freedman, S., \& Enright, R. D. (1996). Forgiveness as an intervention goal with incest survivors. Journal of Consulting and Clinical Psychology, 64, 983-992.

Gilbert, D. T., Pinel, E. C., Wilson, T. D., Blumberg, S. J., \& Wheatley, T. P. (1998). Immune neglect: A source of durability bias in affective forecasting. Journal of Personality and Social Psychology, 75, 617638

Gorsuch, R. L., \& Hao, J.Y. (1993). Forgiveness: An exploratory factor analysis and its relationships to religious variables. Review of Religious Research, 34, 333-347.

Greenberg, M. A. (1995). Cognitive processing of traumas: The role of intrusive thoughts and reappraisals. Journal of Applied Social Psychology, 25, 1262-1296.

Harris, C. R. (2002). Sexual and romantic jealousy in heterosexual and homosexual adults. Psychological Science, 13, 7-12.

Higgins, E. T. (1987). Self-discrepancy: A theory relating self and affect. Psychological Review, 94, 319-340.

Holman, E. A., \& Silver, R. C. (1996). Is it the abuse or the aftermath? A stress and coping approach to understanding responses to incest. Journal of Social and Clinical Psychology, 15, 318-339.

John, O. P., Donahue, E. M., \& Kentle, R. (1992). The Big Five Inventory: Versions 4a and 54 (Tech. Report). Berkeley: University of California, Institute of Personality and Social Research.

Kenny, D. A. (1995). The effect of nonindependence on significance testing in dyadic research. Personal Relationships, 2, 67-75.

Lazarus, R. S. (1995). Vexing research problems inherent in cognitive-mediational theories of emotion-and some solutions. Psychological Inquiry, 6, 183-196.

Lieberman, M., \& Gilbert, D. T. (1998). The role of affective forecasting in mispredictions of forgiveness. Poster presented at the 10th annual convention of the American Psychological Society, Washington, DC.

Lyubomirsky, S., \& Nolen-Hoeksema, S. (1993). Self-perpetuating properties of dysphoric rumination. Journal of Personality and Social Psychology, 65, 339-349.

Lyubomirsky, S., \& Nolen-Hoeksema, S. (1995). Effects of selffocused rumination on negative thinking and interpersonal problem solving. Journal of Personality and Social Psychology, 69, 176-190.

Mauger, P. A., Perry, J. E., Freeman, T., Grove, D. C., McBride, A. G., \& McKinney, K. E. (1992). The measurement of forgiveness: Preliminary research. Journal of Psychology and Christianity, 11, 170-180.

McCullough, M. E. (2000). Forgiveness as human strength: Theory, measurement, and links to well-being. Journal of Social and Clinical Psychology, 19, 43-55.

McCullough, M. E., Bellah, C. G., Kilpatrick, S. D., \& Johnson, J. L. (2001). Vengefulness: Relationships with forgiveness, rumina- tion, well-being, and the big five. Personality and Social Psychology Bulletin, 27, 601-610.

McCullough, M. E., Hoyt, W. T. \& Rachal, K. C. (2000). What we know (and need to know) about assessing forgiveness constructs. In M. E. McCullough, K. I. Pargament, \& C. E. Thoresen (Eds.), Forgiveness: Theory, research, and practice (pp. 65-88). New York: Guilford.

McCullough, M. E., Rachal, K. C., Sandage, S. J., Worthington, E. L., Brown, S. W., \& Hight, T. (1998). Interpersonal forgiving in close relationships: II. Theoretical elaboration and measurement. Journal of Personality and Social Psychology, 75, 1586-1603.

McCullough, M. E., Worthington, E. L., \& Rachal, K. C. (1997). Interpersonal forgiving in close relationships. Journal of Personality and Social Psychology, 73, 321-336.

McGary, H. (1989). Forgiveness. American Philosophical Quarterly, 26, 343-351.

Nolen-Hoeksema, S. (1991). Responses to depression and their effects on the duration of depressive episodes. Journal of Abnormal Psychology, 100, 569-582.

Parkinson, B., \& Manstead, A. S. R. (1992). Appraisal as a cause of emotion. In M. S. Clark (Ed.), Review of personality and social psychology (Vol. 13, pp. 122-149). New York: Russell Sage.

Parkinson, B., \& Manstead, A. S. R. (1993). Making sense of emotion in stories and social life. Cognition and Emotion, 7, 295-323.

Peterson, C., Maier, S. F., \& Seligman, M. E. (1993). Learned helplessness: A theory for the age of personal control. New York: Oxford University Press.

Peterson, C., \& Seligman, M. E. (1984). Causal explanations as a risk factor for depression: Theory and evidence. Psychological Review, 91, 347-374

Radloff, L. F. (1977). The CES-D Scale: A self-report depression scale for research in the general population. Applied Psychological Measurement, 1, 385-401.

Rosenberg, M. (1965). Society and the adolescent self-image. Princeton, NJ: Princeton University Press.

Russell, D., \& McAuley, E. (1986). Causal attributions, causal dimensions, and affective reactions to success and failure. Journal of Personality and Social Psychology, 50, 1174-1185.

Spielberger, C. D., Jacobs, G., Russell, S., \& Crane, R. S. (1983). Assessment of anger: The state-trait anger scale. In J. N. Butcher \& C. D. Spielberger (Eds.), Advances in personality assessment (pp. 161189). Hillsdale, NJ: Lawrence Erlbaum.

Stuckless, N., \& Goranson, R. (1992). The vengeance scale: Development of a measure of attitudes toward revenge. Journal of Social Behavior and Personality, 7, 25-42.

Thoresen, C. E., Harris, A. H. S., \& Luskin, F. (2000). Forgiveness and health: An unanswered question. In M. E. McCullough, K. I. Pargament, \& C. E. Thoresen (Eds.), Forgiveness: Theory, research, and practice (pp. 254-280). New York: Guilford.

Watson, D., Hubbard, B., \& Wiese, D. (2000). Self-other agreement in personality and affectivity: The role of acquaintanceship, trait visibility, and assumed similarity. Journal of Personality and Social Psychology, 78, 546-558.

Received April 9, 2002

Revision accepted July 25, 2002 